\title{
COMPARISON OF SAMPLING TECHNIQUES FOR ISOTOPIC ANALYSIS OF SHALLOW MARINE CARBONATES
}

\author{
Psomiadis D. ${ }^{1,2}$, Dotsika E. ${ }^{1}$, Albanakis K. ${ }^{2}$, Zisi N. ${ }^{1}$, Poutoukis D. ${ }^{3}$ \\ and Lazaridis A. ${ }^{4}$ \\ ${ }^{1}$ Stable Isotope Unit, Institute of Materials Science, NCSR Demokritos, Agia Paraskevi Attiki, Greece, \\ dapsom@ims.demokritos.gr,edotsika@ims.demokritos.gr,nzissi@ims.demokritos.gr \\ ${ }^{2}$ Department of Physical and Environmental Geography, School of Geology, \\ Aristotle University of Thessaloniki, Greece, albanaki@geo.auth.gr \\ ${ }^{3}$ General Secretariat for Research and Technology, Mesogion 14-18, 11510 Athens, Greece, \\ dpoutoukis@gst.gr \\ ${ }^{4}$ Greek Ministry of National Education and Religious Affairs, Andrea Papandreou 37, \\ Marousi 15180 Greece
}

\begin{abstract}
Recent studies have widely used beachrock samples for isotopic and dating techniques; however the source matrix of the analyzed samples varied. Bulk rock material, skeletal fragments, allochems and pure cement have been used in different studies. Basic parameters of each technique are crucial for the accuracy and the reliability of the obtained results, affecting each time important agents. This study includes isotopic analyses $\left(\delta^{13} C, \delta^{18} O\right)$ of marine carbonates (beachrocks) from the coasts of N. Greece (Thassos island). The sub-sampling was carried out along beachrock cores, following different procedures and protocols. The obtained results show in general expecting differences in isotopic composition of the samples. Experiments that included heating of the samples show an influence on oxygen isotope. Different separation and selection of sampling material affect majorly the isotope of carbon $\left({ }^{13} \mathrm{C}\right)$. Differences are attributed to the origin of the carbonate component of the analyzed material. The study indicates that a full-range of comparison experiments should be implemented in order to define in detail the analytical parameters that affect isotopic measurements. The results of that kind of studies will be used not only in stable isotope analyses but also in a variety of methods used in palaeoclimatic and palaeoenvironmental research.
\end{abstract}

Key words: marine cements, beachrock, sampling, stable isotopes.

\section{Introduction}

The rapid cementation of beach sediments in the intertidal zone leads to the formation of characteristic synsedimentary lithified structures termed as beachrocks (Rey et al., 2004). Beachrock is a hard, rocky, coastal formation, lithified in the intertidal zone by carbonate cements. The importance of beachrocks can be rendered in three main topics: their impacts on coastal evolution (Cooper 1991), their role as sea-level indicators (Hopley, 1986; Caldas et al., 2006) and the information they contain regarding the coastal processes of cementation and palaeoenvironmental evolution (Longman, 1980; Vieira and De Ros, 2006). 
There have been numerous mechanisms proposed for beachrock cementation by calcium carbonate (Scholten, 1972):

1. Abiotic precipitation from evaporation of sea water (Ginsburg, 1953; Emery et al., 1954; Stoddart and Cann, 1965; Moore and Billings, 1971; Milliman, 1974; Beier, 1985).

2. Abiotic precipitation from ground water (Russell, 1962, 1963; Deboo, 1962; Russell and McIntire, 1965).

3. Abiotic precipitation in the salt water-fresh water mixing zone (Schmalz, 1971; Moore, 1973).

4. CO2 degassing from beach ground waters (Hanor, 1978).

Several studies have been carried out using the isotopic signature of carbonate cements in the marine-phreatic environment. Authors have used in the past stable isotopes (Beier, 1985; Chaves and Sial, 1998; Friedman, 2004; Holail and Rashed, 1992; Land, 1970; Vieira et al., 2006) based on whole-rock samples and isolated cement. The case of whole-rock sampling for isotopic analysis carries wide erroneous parameters which may lead to false isotopic fingerprints for the carbonate precipitates and thus to misleading conclusions on diagenetic environments and palaeoclimatic interpretations. For reference, Vieira et al. (2006) attempted to determine the origin of Holocene beachrocks in NE Brazilian coast by measuring the isotopic composition of bulk-rock samples after defining their cement petrography. The range of isotopic values reached up to $11,4 \%$ and $3,9 \%$ or $\delta^{13} \mathrm{C}$ and $\delta^{18} \mathrm{O}$ respectively, indicating "contaminated" samples by allogenic carbonates. Also, Land (1970) studied the diagenetic features between phreatic and vadose beachrocks from Bermuda, indicating a wide range of $\delta^{13} \mathrm{C}$ values $\left(2,2\right.$ to $-6,8 \%$ ) and relatively lower differences in $\delta^{18} \mathrm{O}$. Other studies used beachrock cement (e.g. Chaves and Sial, 1998; Calvet et al., 2003; Spurgeon et al., 2003; Friedman, 2004; Guerra et al., 2005) isolated by simple techniques, achieving lower range of isotopic values however showing wide differences between same environment of precipitation.

This study aims to compare the isotopic composition of specific levels inside a carbonate formation like beachrock. In particular, samples from the same level were analyzed, differing from each other on the sampled material. Bulk rock sample, macroscopic and microscopic selection, stirred and dried material are some of the selected methods of sample extraction for isotopic analysis. The results are plotted on diagrams and compared, in order to evaluate the reliability and suitability of sampling methods for isotopic analysis. Samples were taken from the same level of the formation in order to avoid differences of values originated in different precipitation conditions.

\section{Setting of the study area}

The studied beachrock used in this work is located in Thassos Island (N. Greece), in Northern Aegean Sea. The study area is located at the west coast of the island, between Skala Sotira and Skala Kallirachis villages (Fig. 1). The beach is $375 \mathrm{~m}$ long and reaches width of $25 \mathrm{~m}$ (Psomiadis et al., 2009a). Coastal sediments are fine to medium well graded sand with some gravels on the south side where a stream is discharging.

The prevalent rocks in the area are gneiss and marbles. The basins that end up to the study area include Holocene sediments, Miocene marbles, marbles and gneiss alternations and Maries gneiss (Mountrakis, 1985). Two local ephemeral streams end up to the study beach, with a total length of $26,48 \mathrm{~km}$, which cross carbonate rocks and transfer similar sediments to the coast. The area of Thassos is characterized by coastal - marine climatic type, transitional to continental climate (high sum- 


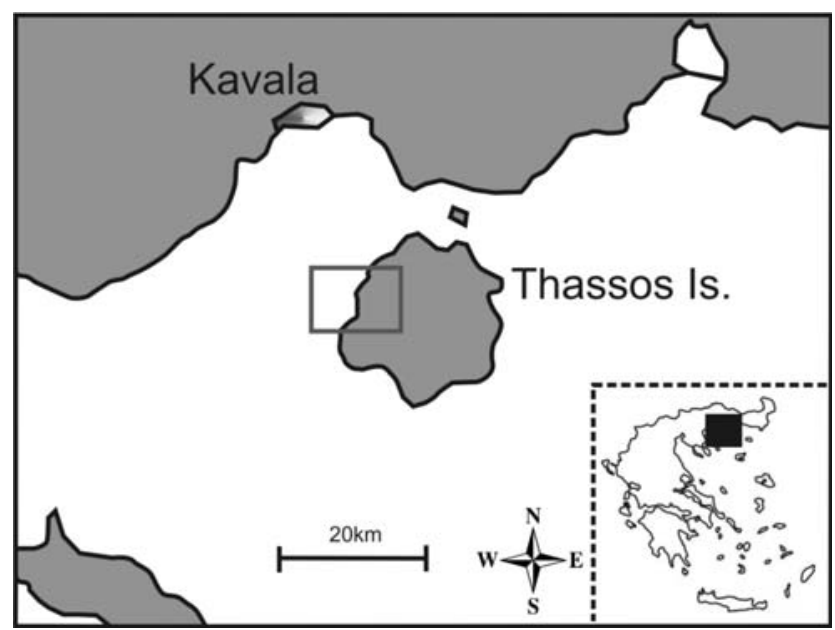

Fig. 1: Simplified map showing the area of study. The studied beachrock is located at the west coast of Thassos Island, between Skala Sotira and Skala Kallirachis villages.

mer temperature, storms), due to the slight distance of the island from the coast of Macedonia at the north. The average annual temperature is $15,8^{\circ} \mathrm{C}$, the average annual precipitation is $770 \mathrm{~mm}$ and the prevalent wind direction is NW for the western part of the island (study area). The exposed beachrock is located in the swash zone and dips gently seawards (mean $5^{\circ}$ ), following the arrangement of the beach. The main body of the formation has a total length of $305 \mathrm{~m}$ and exposure width $2-10 \mathrm{~m}$. The height of the beachrock at its underwater face reaches up to $70 \mathrm{~cm}$. This face is quite steep and has been undercut in many places, resulting in cracking, collapsing, even in displacement of blocks of the formation. Ultra-sonic velocities recorded that deeper layers are less porous than surficial, indicating older age at the bottom (Psomiadis et al., 2009b). At the north end, a jetty separates the study beach from the prolongation of the coastline at the north.

\section{Methods}

\subsection{General}

Beachrock formation from S.Kallirachis beach (Thassos Island, N. Greece, Fig. 1) was drilled and two cores were used in the experimental procedure. The cores were 8 and $20 \mathrm{~cm}$ long each and their diameter was $2.5 \mathrm{~cm}$. Whole-rock samples were separated from the cemented sediments. The different procedures of sample handling included specific parameters that may cause isotopic fractionation (e.g. temperature). The techniques are separated to mechanical and physico-chemical. The first group consists of a) whole-rock grinding, b) macroscopic separation by light grinding, vibration and selection of pale dry grapes, c) microscopic separation by stereo-microscopic selection of carbonate grains, and d) microscopic selection of quartz grains with carbonate cement coating. The physico-chemical procedures included a) whole-rock processing by light grinding, dilution in distilled water by stirring, extraction of $\mathrm{CO}_{3}{ }^{-}$solution and drying in room temperature (approx. 48h), and b) whole-rock processing by light grinding, dilution in distilled water by stirring, extraction of $\mathrm{CO}_{3}^{-}$solution and drying in oven at $70^{\circ} \mathrm{C}$ for $24 \mathrm{~h}$. All samples were grinded to powder after processing and $\delta^{13} \mathrm{C}$ and $\delta^{18} \mathrm{O}$ isotopic ratios were measured (vs. PDB standard) on a Thermo Delta V Plus isotope ratio mass spectrometer equipped with a GasBench II device at Stable Isotope Unit, I.M.S., NCSR Demokritos, 


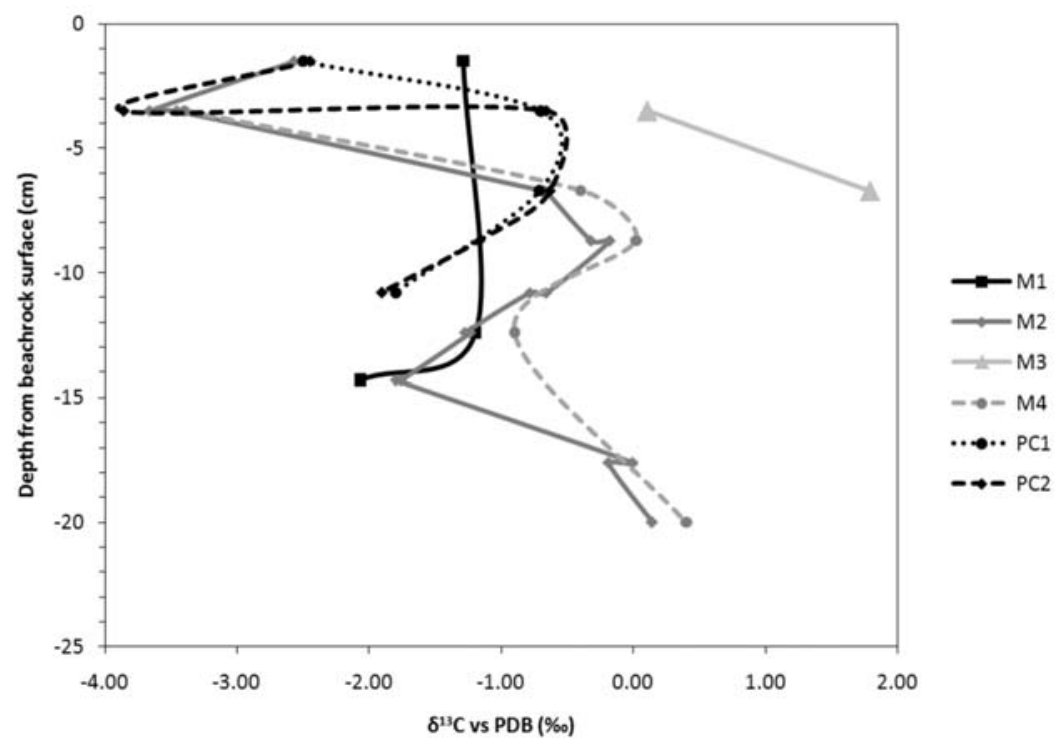

Fig. 2: Carbon isotopic variation of beachrock samples, processed by 6 different techniques (4 mechanical and 2 physicochemical). M1: whole-rock grinding, M2: macroscopic separation by light grinding, vibration and selection of pale dry grapes, M3: microscopic separation by stereo-microscopic selection of carbonate grains, M4: microscopic selection of quartz grains with carbonate cement coating, PC1: whole-rock processing by light grinding, dilution in distilled water by stirring, extraction of $\mathrm{CO}^{-}$solution and drying in room temperature (approx. 48h), PC2: whole-rock processing by light grinding, dilution in distilled water by stirring, extraction of $\mathrm{CO}^{-}$solution and drying in oven at $70^{\circ} \mathrm{C}$ for $24 \mathrm{~h}$.

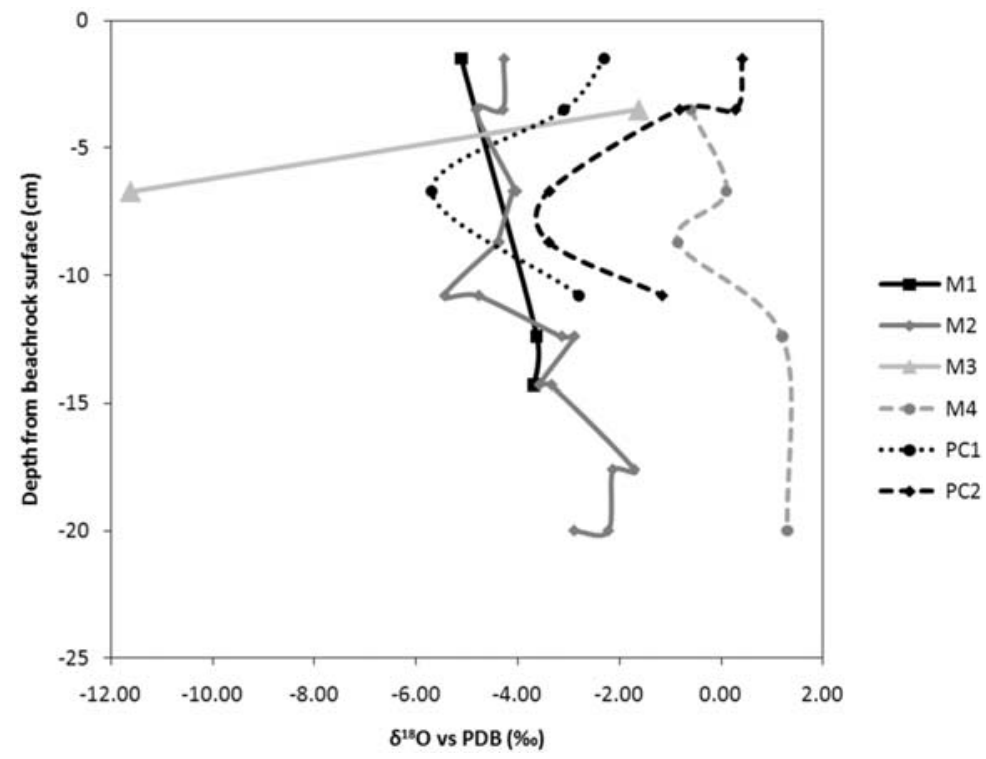

Fig. 3: Oxygen isotopic variation of beachrock samples, processed by 6 different techniques ( 4 mechanical and 2 physicochemical). Legend same as Figure 2. The two cores are correlated relatively to the beachrock surface, in order to have one reference depth for all samples. The number of samples per technique varies, depending on the physical or chemical tolerance of the material during the laboratory experimental processing. 
Athens, after addition of $\mathrm{H}_{3} \mathrm{PO}_{4}$ for $\mathrm{CO}_{2}$ production at $72^{\circ} \mathrm{C}$. The standards used for comparison were NBS 19 and NBS 18 carbonates and an internal Carrara marble standard.

\section{Conclusions-Results}

Carbon and oxygen isotopic composition of the samples was plotted in diagrams versus their depth from beachrock surface (Fig. 2 and 3). Isotopic variation of $\delta^{13} \mathrm{C}$ indicates a general similarity for most techniques, with a light divergence for M1 and a total alteration for M3. Except from the fact that these two techniques included the fewer samples, resulting in lower analytical resolution, their differentiation from the other techniques could be attributed to material composition (especially for M3) as the microscopic grain selection results in more thorough carbonate material separation for analysis. Regarding the oxygen isotopic variation, the observed alterations can be dissociated in two basic causes: either physicochemical implications through processing (temperature, PC1 vs PC2) or material composition (M1, M2 vs M4). In particular, the physicochemical techniques reach a good agreement in variation but they show an alteration $\left(\delta^{18} \mathrm{O}\right.$ enrichment in PC2), which is attributed to possible temperature effect on diluted and re-precipitated carbonate crystals during processing (Clayton, 1961). Techniques M1 and M2 gave similar results, whereas M4 follows same isotopic variation versus depth relatively to $\mathrm{M} 1$ and $\mathrm{M} 2$ but shows a $\delta^{18} \mathrm{O}$ enrichment, probably due to different material composition (totally bulk material for M1 and M2 versus carbonate coating around quartz grains for M4. M3 is presented irregular to the other techniques in that case too.

In conclusion, isotopic composition of whole-rock beachrock samples is affected in different intensity by the experimental processing during preparation for analysis. Carbon and oxygen isotopes show different variation due to their sensitivity to physicochemical agents. The material composition affects greatly $\delta^{13} \mathrm{C}$, while $\delta^{18} \mathrm{O}$ is influenced mostly by temperature, and secondly by the purity of the carbonate material. Further research should focus on specific parameters like mineralogy of cement, affecting the isotopic fingerprint of carbonate cements.

\section{Acknowledgments}

The authors would like to thank Mr. Paltzoglou A. and Mr. Zafeiriadis C. for their handful assistance during drilling.

\section{References}

Beier, J.A., 1985. Diagenesis of Quaternary Bahamian beachrock: petrographic and isotopic evidence, Journal of Sedimentary Petrology, 55 (5), 755-761.

Caldas, L.H.O., Stattegger, K., Vital, H., 2006. Holocene sea-level history: Evidence from coastal sediments of the northern Rio Grande do Norte coast, NE Brazil. Marine Geology, 228, 39-53.

Calvet, F., Cabrera, M.C., Carracedo, J.C., Mangas, J., Pérez-Torrado, F.J., Recio, C., Travé, A., 2003. Beachrocks from the island of La Palma (Canary Islands, Spain). Marine Geology, 197 (1-4), 75-93.

Chaves, N.S., Sial, A.N., 1998. Mixed oceanic and freshwater depositional conditions for beachrocks of northeast Brazil: Evidence from carbon and Oxygen isotopes. International Geology Review, 40 (8), 748-754.

Clayton, R.N., 1961. Oxygen isotope fractionation between calcium carbonate and water. The Journal of Chemical Physics, 34 (3), 724-726.

Cooper, G.A., 1991. Beachrock formation in low latitudes: implications for coastal evolutionary models. Marine Geology, 98, 145-154. 
Deboo, P.B., 1962. A preliminary petrographic study of beach rock. Natl. Coastal and Shallow Water Research Conf. (1 st), 456-458.

Emery, K.O., Tracey, J.I., Jr., Ladd, H.S., 1954. Geology of Bikini and nearby atolls. U.S. Geol. Survey Prof. Pap. 260-A, 265 pp.

Friedman, G.M., 2004. Holocene chronostratigraphic beachrocks and their geologic climatic significance. Geochemical Investigations in Earth and Space Science: A Tribute to Isaac R. Kaplan, 125-142.

Ginsburg, R.N., 1953. Beach rock in South Florida. Journal of Sedimentary Petrology, 23, 85-92.

Guerra, N.C., Kiang, C.H., Sial, A.N., 2005. Carbonate cements in contemporaneous beachrocks, Jaguaribe beach, Itamaracá island, northeastern Brazil: Petrographic, geochemical and isotopic aspects. Anais da Academia Brasileira de Ciencias, 77 (2), 343-352.

Hanor, J.S., 1978. Precipitation of beachrock cements: mixing of marine and meteoric waters vs. $\mathrm{CO}_{2}$ degassing. Journal of Sedimentary Petrology, 48, 489-501.

Holail, H., Rashed, M., 1992. Stable isotopic composition of carbonate-cemented recent beachrock along the Mediterranean and the Red Sea coasts of Egypt. Marine Geology, 106 (1-2), 141-148.

Hopley, D., 1986. Beachrock as a sea-level indicator. In: Van de Plassche O (ed) Sea-level Research. Galliard Printers, Great Yarmouth, 157-173.

Land, L.S., 1970. Phreatic versus vadose meteoric diagenesis of limestones: Evidence from a fossil water table. Sedimentology, 14, 175-185.

Longman, M.W., 1980. Carbonate diagenetic textures from nearsurface diagenetic environments. American Association of Petroleum Geologists Bulletin, 64(4), 461-487.

Milliman, J.D., 1974. Marine Carbonates. Springer-Verlag, Berlin, 375 pp..

Moore, C.H., 1973. Intertidal carbonate cementation Grand Cayman, West Indies. Journal of Sedimentary Petrology, 43, 591-602.

Moore, C.H., Jr., Billings, G.K., 1971. Preliminary model of beachrock cementation, Grand Cayman island, B.W.I. In: Bricker, O.P. (Ed.), Carbonate Cements. Johns Hopkins Press, Baltimore, MD, 4043.

Mountrakis, D., 1985. Geology of Greece. University Studio Press, Thessaloniki, 27-35 (in greek).

Psomiadis, D., Tsourlos, P., Albanakis, K., 2009a. Electrical Resistivity Tomography mapping of beachrocks: application to the island of Thassos (N. Greece). Environmental Earth Sciences, 59(1), 233-240, doi: 10.1007/s12665-009-0021-9.

Psomiadis, D., Vogiatzis, D., Albanakis, K., Christaras, V., Dotsika, E., Zisi, N., 2009b. Valuation of beachrock formation through ultrasonic pulse technique. A method to compare porosities in horizontal and vertical aspects. Geophysical Research Abstracts, Vol. 11, EGU2009-1472, Vienna, Austria.

Rey, D., Rubio, B., Bernabeu, A.M., Vilas, F., 2004. Formation, exposure, and evolution of a high-latitude beachrock in the intertidal zone of the Corrubedo complex. Sedimentary Geology, 169, 93-105.

Russell, R.J., 1962. Origin of beach rock. Zeitschrift fur Geomophologie, 6, 1-16.

Russell, R.J., 1963. Beach rock. Journal of Tropical Geography, 17, 24-27.

Russell, R.J., McIntire, W.G., 1965. Southern hemisphere beach rock. Geogr. Rev. 55, 17-45.

Schmalz, R.F., 1971. Formation of beachrock at Eniwetok Atoll, In: Bricker P (ed) Carbonate Cements. Johns Hopkins Press, Baltimore, MD, 17-24.

Scholten, J.J., 1972. Beach rock: a literature study with special reference to the recent literature. Zentralbl. Geol. Palaontol. Teil I, 351-368.

Spurgeon, D., Davis Jr., R.A., Shinnu, E.A., 2003. Formation of 'Beach Rock' at Siesta Key, Florida and 
its influence on barrier island development. Marine Geology, 200 (1-4), 19-29.

Stoddart, D.R., Cann, J.R., 1965. Nature and origin of beach rock. Journal of Sedimentary Petrology, 56, 422-428.

Vieira, M.M., De Ros, L.F., 2006. Cementation patterns and genetic implications of Holocene beachrocks from northeastern Brazil. Sedimentary Geology, 192, 207-230.

Vieira, M. , Sial, A., de Ros, L., 2006. Origin of Holocene Beachrock Cements in Northeastern Brazil Revealed from Carbon and Oxygen Isotopes. V South American Symposium on Isotope Geology, IGCP 478, Montevideo, Uruguay. 